\title{
HUBUNGAN TINGKAT PENGETAHUAN DENGAN KEPATUHAN PEMAKAIAN ALAT PELINDUNG DIRI PETUGAS CLEANING SERVICE DI RUMAH SAKIT UMUM BANGLI TAHUN 2019
}

\author{
Ni Made Warmuni ${ }^{1}$, Ni Ketut Rusminingsih ${ }^{2}$
}

\begin{abstract}
Cleaning service personnel in working in hospitals are not fully equipped with personal protective equipment or do not adhere to using personal protective equipment so as to cause workplace accidents. This study aims to determine the relationship between the level of knowledge and compliance with the use of personal protective equipment cleaning service officers at Bangli General Hospital. The instrument used was a questionnaire containing a statement of knowledge about personal protective equipment and a checklist of observations about the complete use of personal protective equipment. The type of research used in this study is the cross sectional approach. Samples were taken with a total sample population of 36 cleaning service officers working at Bangli General Hospital. Research analysis uses univariate analysis for the level of knowledge and compliance with the use of personal protective equipment. Bivariate analysis using the chi-square statistical test and contingentcy coefficient. The results of the study showed that there was a relationship between the level of knowledge and compliance with the use of cleaning service personal protective equipment ( $p=0.001 ; a=0.05)$. The cleaning service officer is expected to comply with the standard operating procedures for the use of personal protective equipment so that safety and security are created in work and the application of occupational safety and health to the hospital cleaning service personnel.
\end{abstract}

Keywords: knowledge; compliance with the use of personal protective equipment; occupational Health and Safety.

\section{PENDAHULUAN}

Rumah Sakit penuh dengan bahaya-bahaya potensial yang disebabkan oleh berbagai faktor seperti faktor biologi, kimia, fisik, ergonomi dan faktor lainya yang menyebabkan penyakit akibat kerja dan kecelakaan akibat kerja.(1) Kecelakaan kerja merupakan kejadian tidak terduga dan tidak diinginkan baik kecelakaan akibat langsung pekerjaan maupun kecelakaan yang terjadi di tempat kerja (2). Seperti yang diungkapkan oleh (3), bahwa setiap tahunnya ratusan 
orang terluka atau terbunuh akibat kecelakaan kerja, cidera atau kematian yang terjadi karena pekerja tidak menggunakan alat pelindung diri saat bekerja. Rumah sakit harus memikirkan agar para pekerja termasuk petugas cleaning service terhindar dari bahaya risiko di tempat kerja. Salah satu cara untuk menanggulangi faktor tersebut adalah dengan pemakaian alat pelindung diri.(4) Petugas cleaning service adalah petugas yang selalu menjaga kebersihan dan keamanan rumah sakit. Berdasarkan laporan K3RS terdapat 4 (empat) orang petugas cleaning service yang mengalami kecelakaan kerja pada saat melaksanakan tugas membersihkan areal rumah sakit dimana petugas cleaning service tidak lengkap memakai alat pelindung diri. Tujuan dari penelitian ini yaitu (1) Untuk mengetahui tingkat pengetahuan tentang APD petugas cleaning service, (2) Untuk mengetahui kepatuhan pemakaian APD petugas cleaning service, (3) Untuk mengetahui hubungan tingkat pengetahuan dengan kepatuhan pemakaian alat pelindung diri petugas cleaning service di Rumah Sakit Umum Bangli.

\section{METODE}

Jenis penelitian adalah observasional dengan metode cross sectiona yaitu penelitian untuk mempelajari dinamika hubungan korelasi antara faktor-faktor risiko dengan efeknya dengan cara pendekatan observasi dan pengumpulan data pada saat yang sama atau sekaligus(5). Penelitian ini dilakukan pada bulan Februari sampai dengan Juni 2019. Lokasi Penelitian dilakukan di Rumah Sakit Umum Bangli. Teknik penentuan sampel dengan menggunakan total populasi sampel yaitu seluruh petugas cleaning service yang bekerja di RSU Bangli yang berjumlah 36 orang. Data primer dikumpulkan dari hasil wawancara. Data sekunder diambil dari buku profil Rumah Sakit Umum Bangli Tahun 2018.(6) Cara pengumpulan data dengan melakukan wawancara dengan lembar kuesioner yang terdiri dari 12 pertanyaan yang terdiri dari 3 (tiga) option pernyataan yang diberi skor nilai, hasil penilaian diperoleh tingkat pengetahuan (1) Kategori pengetahuan 
baik nilai pengetahuan $>75 \%$, (2) Kategori pengetahuan cukup mempunyai nilai pengetahuan $60 \%$ $75 \%$, (3) Kategori pengetahuan kurang mempunyai nilai pengetahuan $<60$ \%.(7) Kepatuhan pemakaian APD dilakukan pengamatan dengan lembar ceklist tentang kepatuhan kategori baik sesuai prosedur pemakaian alat pelindung diri memperoleh nilai > $70 \%-100 \%$ petugas mengikuti prosedur pemakaian APD dan kurang patuh memperoleh nilai $<69 \%$ petugas mengikuti prosedur pemakaian APD (8). Analisis univariat untuk mengetahui tingkat pengetahuan dan kepatuhan pemakaian APD petugas cleaning service di rumah sakit. Analisis bivariat untuk mencari hubungan tingkat pengetahuan dan kepatuhan pemakaian alat pelindung diri dengan menggunakan uji statistik
Chi-squre dan Contingency Coefficient dengan taraf signifikansi yaitu 95\% dengan nilai kemaknaan 5\%. Interpretasi jika Ho ditolak dan $\mathrm{Ha}$ diterima bila didapat $\mathrm{p}<0,05$ dan Ho diterima dan $\mathrm{Ha}$ ditolak bila didapatkan $\mathrm{p}>0,05$.

\section{HASIL DAN PEMBAHASAN}

Petugas cleaning service yang bekerja di RSU Bangli, terdiri dari 36 orang yang berjenis kelamin wanita 75\%,laki-laki25\%. (6) Berdasarkan wawancara dengan menggunakan kuesioner terhadap 36 orang petugas cleaning service diperoleh nilai kategori pengetahuan masing-masing petugas cleaning service tentang manfaat penggunaan pemakaian APD. Hasil analisis dapat dilihat pada tabel 1 dibawah ini. 
Tabel 1

Analisis Tingkat Pengetahuan

Petugas Cleaning Service Di Rumah Sakit Umum Bangli Tahun 2019

\begin{tabular}{ccc}
\hline Kategori & Jumlah & $\begin{array}{c}\text { Persentase } \\
\text { Tingkat Pengetahuan }\end{array}$ \\
\hline Baik & 23 & 63.9 \\
Cukup & 2 & 5.6 \\
Kurang & 11 & 30.5 \\
\hline Total & 36 & 100.0 \\
\hline
\end{tabular}

Tabel 1 (satu) menunjukkan bahwa pengetahuan kategori baik berjumlah 23 orang 63,9\%, Analisis observasi kepatuhan pemakaian alat pelindung diri petugas cleaning service di RSU Bangli dapat dilihat pada tabel 2 dibawah ini

Tabel 2

Analisis Kepatuhan Pemakaian Alat Pelindung Diri

Petugas Cleaning Service Di Rumah Sakit Umum Bangli Tahun 2019

\begin{tabular}{ccc}
\hline $\begin{array}{c}\text { Kepatuhan Pemakaian } \\
\text { APD }\end{array}$ & Jumlah & Persentase \\
\hline Baik & & $(\%)$ \\
Kurang & 26 & 72.2 \\
Total & 10 & 27.8 \\
\hline
\end{tabular}

Tabel 2 (dua) menunjukkan kategori kepatuhan pemakaian APD baik sesuai prosedur pemakaian APD berjumlah 26 orang $72,2 \%$
Hasil uji statistik diperoleh $\mathrm{p}=$ 0,001; $\mathrm{p}<0,05$ hal ini menyatakan ada hubungan antara tingkat pengetahuan dengan kepatuhan pemakaian alat pelindung diri 
petugas cleaning service di RSU Bangli dan berdasarkan uji Contingency Coefficient diperoleh hasil 0,519 hubungan taraf sedang.

\section{PEMBAHASAN}

Menurut Notoatmodjo (2010)(9) tingkatan pengetahuan adalah pengetahuan seseorang terhadap suatu objek yang mempunyai intensitas tingkatan yang berbeda-beda sehingga seseorang menjadi tahu, memahami, mampu menganalisis dan mampu menerapkannya. Penelitian ini dilakukan untuk mengetahui tingkat pengetahuan petugas cleaning service tentang manfaat penggunaan pemakaian alat pelindung diri. Petugas cleaning service yang memperoleh kategori pengetahuan baik tentang penggunaan APD 63,9\% bahwa mereka mengetahui semua informasi tentang APD, paham semua penggunaan APD sesuai peruntukannya, mampu menerapkan pemakaian APD serta mengetahui risiko bahaya di tempat mereka bekerja. Petugas cleaning service kategori pengetahuan cukup 5,6\% mereka hanya mengetahui informasi APD, tidak paham semua jenis APD sesuai kegunaan dan peruntukannya serta tidak mengerti risiko tidak memakai APD. Petugas cleaning service yang kategori pengetahuan kurang 30,5\%, mereka hanya mengetahui pemakaian APD dari lingkungan teman sejawat tanpa memahami mengerti tentang pemakaian APD serta kurang mengetahui lingkungan mereka bekerja penuh dengan risiko bahaya. Secara umum tingkat pengetahuan petugas cleaning service lebih banyak yang memiliki pengetahuan baik dibandingkan yang memiliki kategori pengetahuan cukup dan kategori pengetahuan kurang.

Berdasarkan PMK No. 27 Tahun 2017(8), prosedur pemakaian kelengkapan APD yang harus dipakai petugas cleaning service dalam bekerja di rumah sakit yaitu mulai dari pemakaian pelindung kepala memakai tudung/penutup kepala, pemakaian pelindung muka hidung \& mulut memakai masker, pemakaian pelindung tangan memakai selop tangan, pelindung 
badan memakai celemek/gaun pelindung dan pemakaian pelindung kaki memakai sepatu karet/boot. Kategori kepatuhan pemakaian APD baik sesuai prosedur pemakaian APD berjumlah 72,2 \%, bahwa petugas cleaning service dalam bekerja di rumah sakit lengkap memakai APD mulai dari pelindung kepala sampai dengan pelindung kaki sesuai jenis, manfaat serta peruntukannya masingmasing, secara benar dan tepat pemakaainnya. Petugas cleaning service yang kurang patuh tidak sesuai prosedur pemakaian APD berjumlah $27,8 \%$ diantaranya petugas cleaning service tersebut hanya memakai APD masker, sarung tangan dan sepatu karet saja, dan ada juga yang memakai masker dan selop tangan saja serta ada yang memakai sepatu karet saja.

Hasil analisis menggunakan uji statistik Chi-square diperoleh hasil $\mathrm{p}=0,001 ; \mathrm{p}<0,05$ hal tersebut menyatakan bahwa terdapat hubungan yang signifikan antara tingkat pengetahuan dengan kepatuhan pemakaian alat pelindung diri petugas cleaning service di RSU
Bangli. Pada hasil Contingency Coefficient menunjukkan tingkat hubungan taraf sedang dengan hasil 0,519. Hasil penelitian ini sejalan dengan (10), yang menyatakan terdapat hubungan yang significant antara tingkat pengetahuan dengan kepatuhan pemakaian APD petugas cleaning service di RS PKU Muhamadiyah Yogyakarta hasil $\mathrm{p}$ $=0,00 ; \mathrm{p}<0,05$.

Bermacam tugas dan pekerjaan petugas cleaning service tentunya tidak terlepas dari risiko bahaya penyakit yang ditimbulkan dan dapat mengganggu keselamatan dan kesehatan jiwa petugas, oleh karena itu petugas cleaning service harus memahami, mengerti, taat dan patuh menerapkan APD dalam bekerja. Untuk meningkatkan pengetahuan tentang APD dan kepatuhan pemakaian alat pelindung diri diperlukan upaya pelayanan kesehatan secara konprehensif pada petugas cleaning service. Menurut (11) tentang K3RS dicantumkan upaya-upaya yang dilakukan untuk pengendalian dan pencegahan risiko akibat kerja dan gangguan kesehatan 
dalam bekerja di rumah sakit, adapun upaya pelayanan tersebut meliputi kegiatan pelayanan promotif, preventif, kuratif dan rehabilitative yang dapat diterapkan pada petugas cleaning service yang bekerja di rumah sakit.

\section{SIMPULAN DAN SARAN}

Berdasarkan pembahasan diatas maka dapat ditarik kesimpulan bahwa (1) Tingkat pengetahuan petugas cleaning service diperoleh kategori pengetahuan baik 63,9\%, kategori pengetahuan cukup 5,6\% dan kategori pengetahuan kurang 30,5\%, (2) Kepatuhan pemakaian APD kategori baik sesuai prosedur $72,2 \%$ dan kategori kepatuhan pemakaian APD kurang patuh tidak sesuai prosedur $27,8 \%$, (3) Ada hubungan tingkat pengetahuan dengan kepatuhan pemakaian APD petugas cleaning service di RSU Bangli. Adapun saran yang dapat diberikan bahwa (1) Diharapkan petugas cleaning service yang bekerja di rumah sakit memperhatikan SPO pemakaian APD sehingga aman dalam bekerja,
(2)Untuk meningkatkan pengetahuan dan kepatuhan pemakaian APD dapat dilakukan dengan penerapan upaya pelayanan K3RS secara konprehensif berkesinambungan pada petugas cleaning service rumah sakit.

\section{DAFTAR PUSTAKA}

1. Hasyim H. Faktor-Faktor Yang Berpengaruh Terhadap Penggunaan Tenaga Kerja Luar Keluarga Pada Usaha Tani Padi Sawah. AgribisnisFakultas Pertanian UniversitasSumatera Utara. Retrieved fromhttps://. jurnal.usu.ac.id/index.php/ceres s/article/view/790. 2015;

2. B B. Panduan Praktis Keselamatan dan Kesehatan Kerja. Yogyakarta: Pustaka Baru Press; 2015.

3. Konya RS, Akpiri RU ON. The Use of Personal Protective Equipment (PPE) among Workers of Five Refuse Disposal Companies within Port Harcourt Metropolis Rivers State Nigeria. Asian J Appl Sci. 2013;1(5):171-9.

4. Kesehatan SM. Keputusan 
Menteri Kesehatan Republik

Indonesia Nomor :

1087/Menkes/SK/VIII/2010

Tentang Standard Kesehatan

dan Keselamatan Kerja Rumah

Sakit. Jakarta: Direktorat Bina

Kesehatan Kerja; 2010.

5. Nazir M. Metode Penelitian.

Bogor: Ghalia Indonesia;

6. Bangli SR. Rumah Sakit Umum

Bangli, 2018 , Profil RSU

Bangli, Bangli. Bangli: RSU

Bangli; 2018.

7. Arikunto. Prosedur Penelitian

Suatu Pendekatan Praktik.

Jakarta: Rineka Cipta; 2006.

8. Kesehatan SMK. No TitlePMK

RI Nomor 27 Tahun 2017.

Pencegahan Dan Pengendalian
Infeks. Jakarta: Kementerian

Kesehatan RI.; 2017.

9. Notoatmodjo S. Promosi

Kesehatan dan Ilmu Perilaku.

Jakarta: Rineka Cipta; 2010.

10. Helen Try Juni Asti. Skripsi, Hubungan Antara Tingkat

Pengetahuan Dengan Kepatuhan Penggunaan APD Pada Petugas

Cleaning Service Di Rumah

Sakit PKU Muhammadiyah

Yogyakarta; Universitas

Muhammadiyah Yogyakarta.;

11. Kesehatan SM. PMK RI Nomor 66 Tahun 2016. Keselamatan Dan Kesehatan Kerja Rumah Sakit. Jakarta: Kementerian Kesehatan RI.; 2016. 